\title{
Hydrothermal Synthesis and Microwave Absorption Properties of Nickel Ferrite/Multiwalled Carbon Nanotubes Composites
}

\author{
Lei Guo ${ }^{1}$, Yusong $\mathrm{He}^{2}$, Dong Chen ${ }^{1}$, Bin Du ${ }^{1}$, Wei Cao ${ }^{1}$, Yadong $\mathrm{Lv}^{2, *}$ and Zhijun Ding ${ }^{1, *}$ \\ 1 State Key Laboratory of NBC Protection for Civilian Research, Beijing 102205, China; \\ guo_study@163.com (L.G.); ch_ever@126.com (D.C.); dubin51979@163.com (B.D.); \\ odysseus1988@126.com (W.C.) \\ 2 College of Polymer Science and Engineering, Sichuan University, Chengdu 610065, China; \\ heyusong@scu.edu.cn \\ * Correspondence: yadonglv@scu.edu.cn (Y.L.); dzj212@163.com (Z.D.)
}

Citation: Guo, L.; He, Y.; Chen, D.; Du, B.; Cao, W.; Lv, Y.; Ding, Z. Hydrothermal Synthesis and Microwave Absorption Properties of Nickel Ferrite/Multiwalled Carbon Nanotubes Composites. Coatings 2021, 11, 534. https://doi.org/ 10.3390/coatings11050534

Received: 20 March 2021

Accepted: 26 April 2021

Published: 30 April 2021

Publisher's Note: MDPI stays neutra with regard to jurisdictional claims in published maps and institutional affiliations.

Copyright: (c) 2021 by the authors. Licensee MDPI, Basel, Switzerland. This article is an open access article distributed under the terms and conditions of the Creative Commons Attribution (CC BY) license (https:// creativecommons.org/licenses/by/ $4.0 /)$.

\begin{abstract}
It is well accepted that the microwave absorption performance of ferrite can be enhanced via the hybridization. However, it is still very challenging to design the hierarchical nanostructure of ferrite hybrids to fabricate wave absorbing composites with both the high efficiency and lightweight. Herein, we successfully realize the in-situ synthesis of nickel ferrite/multiwalled carbon nanotubes ( $\mathrm{NiFe}_{2} \mathrm{O}_{4} / \mathrm{MWCNTs}$ ) hybrids with a large-scale production by the hydrothermal method. The structural characteristics, morphology, electromagnetic and microwave absorption properties were analyzed by $\mathrm{X}$-ray diffraction, scanning electron microscope and vector network analyzer. The morphological study shows that $\mathrm{NiFe}_{2} \mathrm{O}_{4}$ nanoparticles with a small size (tens of nanometers) are coated on the MWCNTs, leading to a three-dimensional hierarchical nanostructure. The $\mathrm{NiFe}_{2} \mathrm{O}_{4} / \mathrm{MWCNTs}$ hybrids show satisfied microwave absorption properties. Typically, the optimized sample shows the minimum reflection loss of $-19 \mathrm{~dB}$ at $11.3 \mathrm{GHz}$, and the bandwidth of the reflectivity below $-10 \mathrm{~dB}$ is $2.5 \mathrm{GHz}$ with a thin thickness of $1.5 \mathrm{~mm}$. This result shall be due to the improved dielectric losses or interface polarization etc. Our results demonstrate a facile approach for the design of ferrite-based microwave absorber to meet the requirements of lightweight, thin-thickness and high efficiency.
\end{abstract}

Keywords: hydrothermal method; nickel ferrite; multiwalled carbon nanotubes; absorbing properties

\section{Introduction}

To date, the development of radar stealth technology has been attached great importance to many countries [1,2]. As one of the main ways to achieve radar stealth, the development of radar absorbing materials has become a major issue of the various countries' military technology. The comprehensive requirements of stealth technology for absorbing materials (primarily about absorbing coating) can be referred to as: thin, wide, light and strong [3-5].

As the microwave absorbing material, ferrite has excellent magnetic properties and high electrical resistivity, and outstanding magnetic loss can appear in a wide frequency range, into which electromagnetic wave is easy to enter and decay rapidly [6-8]. Moreover, high curie temperature and low eddy current loss of ferrite make it suitable for being used as radar absorbing materials especially at high frequencies. However, it also has many shortcomings, such as lower impedance matching, onefold loss absorption mechanism and higher density, which greatly limit the ferrite in the actual applications $[9,10]$.

Carbon nanotubes (CNTs), with large length to diameter ratio, low density, large specific surface area and high electrical conductivity, show good absorbing properties [11-14]. However, the high conductivity of CNTs has also led to the poor absorption caused by the mismatch of interface impedance. Thus, other dielectric or magnetic materials have been used to regulate the impedance of CNTs, such as conductive polymers, magnetic metal or metal oxides. Due to the special structure and dielectric properties of carbon 
nanotubes, the absorbing properties of the composite materials synthesized by carbon nanotubes and other materials has shown good application prospect, such as architecture and aircraft coatings $[15,16]$. For example, CNTs has been combined with $\mathrm{Fe}_{3} \mathrm{O}_{4}$ to enhance their electromagnetic wave absorption performance [17,18]. Lu et al. [17] reported that the reflection loss of $\mathrm{Fe}_{3} \mathrm{O}_{4} / \mathrm{CNTs}$ can reach $-12.62 \mathrm{~dB}$ at $17.72 \mathrm{GHz}$. The interface introduced by $\mathrm{Fe}_{3} \mathrm{O}_{4}$ can not only enhance the magnetic loss, but also create resonance in complex permittivity. Hou et al. [18] also fabricated $\mathrm{Fe}_{3} \mathrm{O}_{4} / \mathrm{CNTs}$ hybrids by a chemical synthesishydrothermal treatment method and obtained a minimum reflection loss of $-18.22 \mathrm{~dB}$ at $12.05 \mathrm{GHz}$. Despite substantial efforts have been devoted to the investigation of CNTs hybrids, the design of the hierarchical nanostructure of the hybrids to take full advantage of the conduction and magnetic loss, as well as the interfacial loss is still very challenging.

Nickel ferrite has been extensively investigated for applications in ferrofluids, microwave devices and magnetic materials etc. Moreover, hydrothermal route has been demonstrated to be a low-cost, rapid and large-production method of synthesizing ferrite powders. As a result, in this contribution, we selected nickel ferrite $\left(\mathrm{NiFe}_{2} \mathrm{O}_{4}\right)$ as a model ferrite material, and successfully synthesized $\mathrm{NiFe}_{2} \mathrm{O}_{4} /$ multiwalled carbon nanotubes (MWCNTs) composite absorbing material through the hydrothermal method. The effect of different reaction conditions for structure and morphology was studied, and the microwave characteristics of the prepared samples was evaluated. Reflection loss evaluations indicated that the composites display good absorbing properties.

\section{Experimental}

\subsection{Materials}

Multiwalled carbon nanotubes (MWCNTs) with diameters of 30-50 nm were used as received. Analytical grade of Ferric nitrate $\left(\mathrm{Fe}\left(\mathrm{NO}_{3}\right)_{3} \cdot 9 \mathrm{H}_{2} \mathrm{O}\right)$, nickel nitrate $\left(\mathrm{Ni}\left(\mathrm{NO}_{3}\right)_{2} \cdot 6 \mathrm{H}_{2} \mathrm{O}\right)$ and sodium hydroxide $(\mathrm{NaOH})$ were used without further purification.

\subsection{In-Situ Synthesis of $\mathrm{NiFe}_{2} \mathrm{O}_{4} / \mathrm{MWCNTs}$ Hybrids}

Spinel nickel ferrite powders with the nominal composition of $\mathrm{NiFe}_{2} \mathrm{O}_{4}$ were hydrothermally synthesized. MWCNTs were added in-situ during the process. First, $1 \mathrm{mmol}$ $\mathrm{Ni}\left(\mathrm{NO}_{3}\right)_{2} \cdot 6 \mathrm{H}_{2} \mathrm{O}, 2 \mathrm{mmol} \mathrm{Fe}\left(\mathrm{NO}_{3}\right)_{3} \cdot 9 \mathrm{H}_{2} \mathrm{O}$ and a certain amount of purified MWCNTs were dissolved in $30 \mathrm{~mL}$ distilled water and ultasonicated for $1 \mathrm{~h}$ to form aqueous solutions. Then, $0.8 \mathrm{~g} \mathrm{NaOH}$ was slowly added to the above solution to coprecipitate $\mathrm{Ni}^{2+}$ and $\mathrm{Fe}^{3+}$ ions by constant stirring and then a brown precipitate was formed. The mixture was stirred vigorously for $30 \mathrm{~min}$, transferred and sealed in a $50 \mathrm{~mL}$ Teflon-lined stainless-steel were autoclaved, and maintained at $100-200{ }^{\circ} \mathrm{C}$ for $2-8 \mathrm{~h}$. The system was cooled to room temperature naturally. The products of $\mathrm{NiFe}_{2} \mathrm{O}_{4} /$ MWCNTs hybrids with the black color were collected by a magnetic field, rinsed with absolute ethanol and deionized water for several times and dried at $60^{\circ} \mathrm{C}$ for $24 \mathrm{~h}$. For comparison, nickel ferrite powders were also prepared using the same procedure.

\subsection{Characterizations}

The crystalline structure of produced materials were examined by $\mathrm{X}$-ray diffractometer ( $X^{\prime}$ Pert PRO, PANalytical, The Netherlands) with $\mathrm{Cu} \mathrm{K} \alpha$ radiation $(\lambda=0.154 \mathrm{~nm})$. Scanning electron microscopy (SEM) (VEGAIIXMUINCN, TESCAN company, Brno, Czech republic) with an acceleration voltage of $20 \mathrm{kV}$ was used to examine the sample morphology and microstructure; electromagnetic parameters were examined by vector network analyzer (HP 8720ES, Agilent Technologies, Santa Clara, CA, USA) with coaxial-line method.

Preparation of samples and testing procedure are as follows: sample powders of the desired substrate paraffin and absorbing agents were weighted, and then absorbents powder was added to the molten paraffin wax and stirred sufficiently, cooled and grinded using a mortar and pestle and then melt-mixing. After repeating this procedure for 3 to 4 times, an appropriate amount of alcohol was added and the mixture was sheared with the high-speed emulsifying machine. After being dried, it was milled into powders and 
pressed into the circular coaxial sample (outer diameter $\Phi 7 \mathrm{~mm}$, inner diameter $\Phi 3 \mathrm{~mm}$, length $2-5 \mathrm{~mm}$ ). Samples were placed in a coaxial test fixture. Calibrated HP 8720 ES vector network analyzer were then used to test specimens at $2-18 \mathrm{GHz}$.

\section{Results and Discussion}

Effects of temperature and reaction time on the sample formation were investigated first. Figure 1 shows the XRD patterns of samples synthesized at different temperature with a reaction time of $2 \mathrm{~h}$. According to the results, samples at lower temperature show a weak, broad peak; when the temperature increases from $100^{\circ} \mathrm{C}$ to $200^{\circ} \mathrm{C}$, the sharp diffraction peaks form for both $\alpha-\mathrm{Fe}_{2} \mathrm{O}_{3}$ and $\mathrm{NiFe}_{2} \mathrm{O}_{4}$, as labeled by filled diamond and filled circle, respectively, in Figure 1. Some characteristic peaks from $\mathrm{NiFe}_{2} \mathrm{O}_{4}$ are fairly weak, which means that the obtained sample is basically a mixture of $\alpha-\mathrm{Fe}_{2} \mathrm{O}_{3}$ and $\mathrm{NiFe}_{2} \mathrm{O}_{4}$.

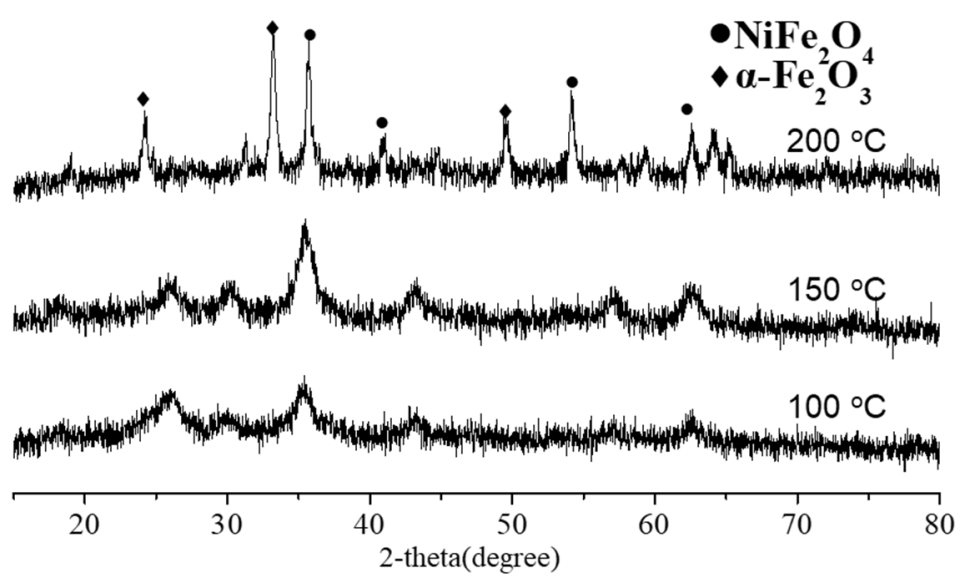

Figure 1. XRD patterns of samples synthesized at different temperature with a reaction time of $2 \mathrm{~h}$. Characteristic peaks for $\alpha-\mathrm{Fe}_{2} \mathrm{O}_{3}$ and $\mathrm{NiFe}_{2} \mathrm{O}_{4}$ are labeled by filled diamond and filled circle, respectively.

Figure 2 shows the XRD patterns of sample powders synthesized at $200{ }^{\circ} \mathrm{C}$ with different reaction time. Comparing the diffractograms with the powder data of $\alpha-\mathrm{Fe}_{2} \mathrm{O}_{3}$ (JCPDS card no. 33-0664) and $\mathrm{NiFe}_{2} \mathrm{O}_{4}$ (JCPDS card no. 10-0325), it can be seen that with the increase of reaction time, the diffraction peaks of $\alpha-\mathrm{Fe}_{2} \mathrm{O}_{3}$ become less and the peak intensity become weaker gradually. When the reaction time is $8 \mathrm{~h}$, the diffraction peaks of $\alpha-\mathrm{Fe}_{2} \mathrm{O}_{3}$ disappear. The sample powder exhibits similar diffraction peaks which correspond to the cubic inverse spinel type lattice of $\mathrm{NiFe}_{2} \mathrm{O}_{4}$. The sharp diffraction peaks corresponding to (111), (220), (311), (222), (400), (422), (511), (440) and (533) planes indicate the good crystallinity of the nanocrystals [2,19].

Figure 3 shows the SEM images of the MWCNTs and $\mathrm{NiFe}_{2} \mathrm{O}_{4} /$ MWCNTs composites produced at 150 and $200{ }^{\circ} \mathrm{C}$. It is obvious that as the temperature rises, more and more ferrites grown on the MWCNTs under the same conditions. The $\mathrm{NiFe}_{2} \mathrm{O}_{4}$ shall be anchored on the surface of MWCNTs through electrostatic interaction during the reaction [20]. Moreover, the transformation of metal ion may occur causing the reduction of the oxygen-containing group on the oxidized CNTs surface and lead to a stronger chemical interaction between $\mathrm{NiFe}_{2} \mathrm{O}_{4}$ and MWCNTs [21]. When the temperature is $20{ }^{\circ} \mathrm{C}$, MWCNTs are completely covered with $\mathrm{NiFe}_{2} \mathrm{O}_{4}$ nanoparticles. This is because the reaction rate is accelerated with the increasing temperature, which is facilitated to the formation and coated of ferrite particles.

SEM images of the $\mathrm{NiFe}_{2} \mathrm{O}_{4} /$ MWCNTs composites synthesized at $200{ }^{\circ} \mathrm{C}$ for $8 \mathrm{~h}$ with different amount of carbon nanotubes are shown in Figure 4. Most ferrites are agglomerate when adding a small amount of MWCNTs, and the distribution of MWCNTs is quite nonuniform. With the increase of the amount of MWCNTs, MWCNTs can be coated uniformly by $\mathrm{NiFe}_{2} \mathrm{O}_{4}$, and the distribution of MWCNTs becomes uniform especially at $0.15 \mathrm{~g}$ of MWCNTs. However, when the amount of MWCNTs is increased to $0.2 \mathrm{~g}$, an 
incomplete coating is observed. The results show that the appropriate amount of carbon nanotubes shall be $0.15 \mathrm{~g}$ and the sample synthesized using $0.15 \mathrm{~g}$ MWCNTs is used for the measurement of electromagnetic parameters in the following part.

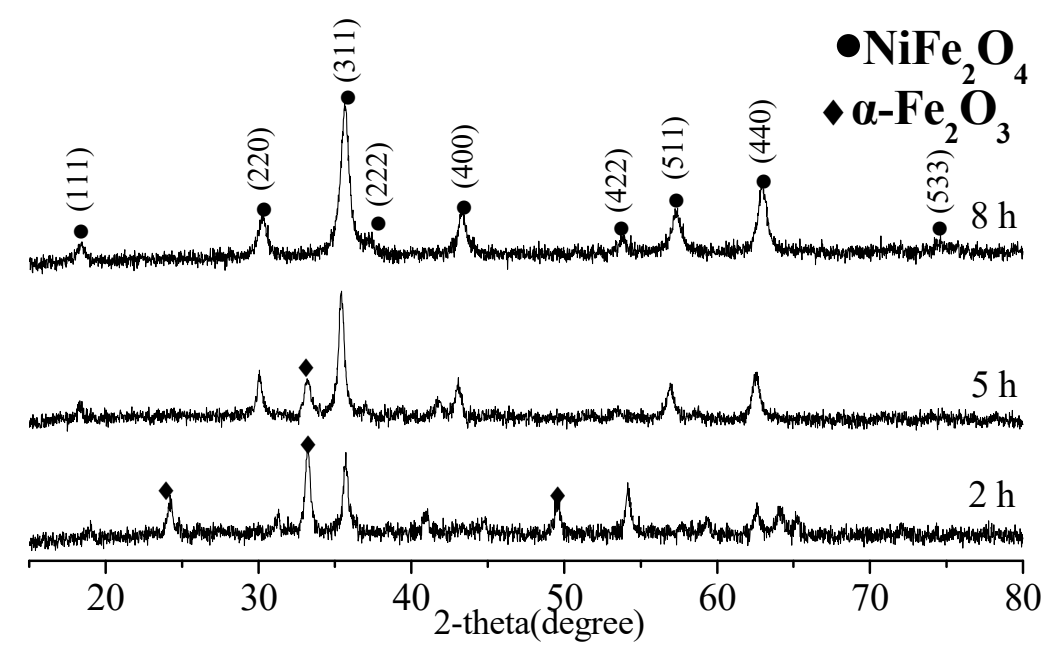

Figure 2. XRD patterns of samples synthesized at $200{ }^{\circ} \mathrm{C}$ with different reaction time. Characteristic peaks for $\alpha-\mathrm{Fe}_{2} \mathrm{O}_{3}$ and $\mathrm{NiFe}_{2} \mathrm{O}_{4}$ are labeled by filled diamond and filled circle, respectively.
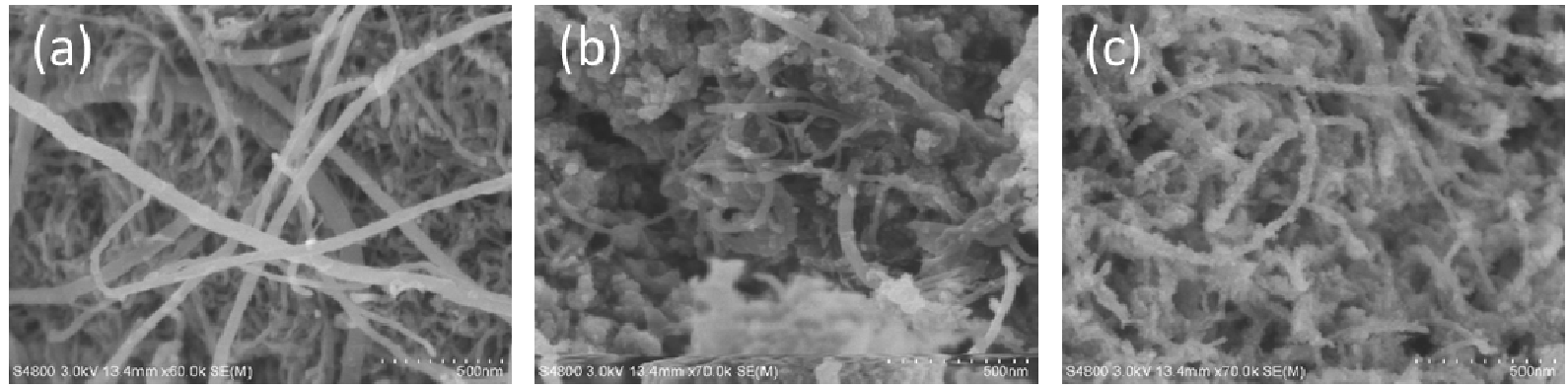

Figure 3. SEM images of the (a) MWCNTs and $\mathrm{NiFe}_{2} \mathrm{O}_{4} / \mathrm{MWCNTs}$ synthesized at (b) $150{ }^{\circ} \mathrm{C}$ and (c) $200{ }^{\circ} \mathrm{C}$, respectively.

The absorption performance of single-absorbing coating is determined by the thickness and the electromagnetic parameters. The theoretical calculations of the single-absorbing coating must consider both the reflection coefficient and the matching of electromagnetic parameters. According to the theory of electromagnetic wave transmission line, when the uniform plane electromagnetic wave whose frequency is $\mathrm{f}$ incident on a vertical conductor surface coated by single-absorbing materials, the reflection loss is related to the normalized input impedance $Z_{\text {in }}$ as $[22,23]$

$$
R=20 \lg \left|\frac{Z_{\text {in }}-1}{Z_{\text {in }}+1}\right|
$$

$Z_{\text {in }}$ represents the input impedance at the absorber/free space interface, which can be expressed as follows:

$$
Z_{\text {in }}=\sqrt{\mu / \varepsilon} \tanh [j(2 \pi f d / c) \sqrt{\mu \varepsilon}]
$$

where $c$ is the velocity of light, $f$ is frequency, $d$ is the thickness of the composite in mm unit, $\varepsilon$ and $\mu$ are the measured data corresponding to the relative complex permittivity $\left(\varepsilon=\varepsilon^{\prime}-j \varepsilon^{\prime \prime}\right)$ and the relative complex permeability $\left(\mu=\mu^{\prime}-j \mu^{\prime \prime}\right)$, respectively.

Figure 5 shows the electromagnetic parameters of the $\mathrm{NiFe}_{2} \mathrm{O}_{4}$ and $\mathrm{NiFe}_{2} \mathrm{O}_{4}$ /MWCNTs composites. The $\mathrm{NiFe}_{2} \mathrm{O}_{4} /$ MWCNTs sample synthesized using $0.15 \mathrm{~g}$ MWCNTs is used. Obviously, for all frequencies between 2 and $18 \mathrm{GHz}$, the real and imaginary parts of complex permittivity of the composite samples increase significantly. The real part of the complex permeability increases, while the imaginary part decreases. 

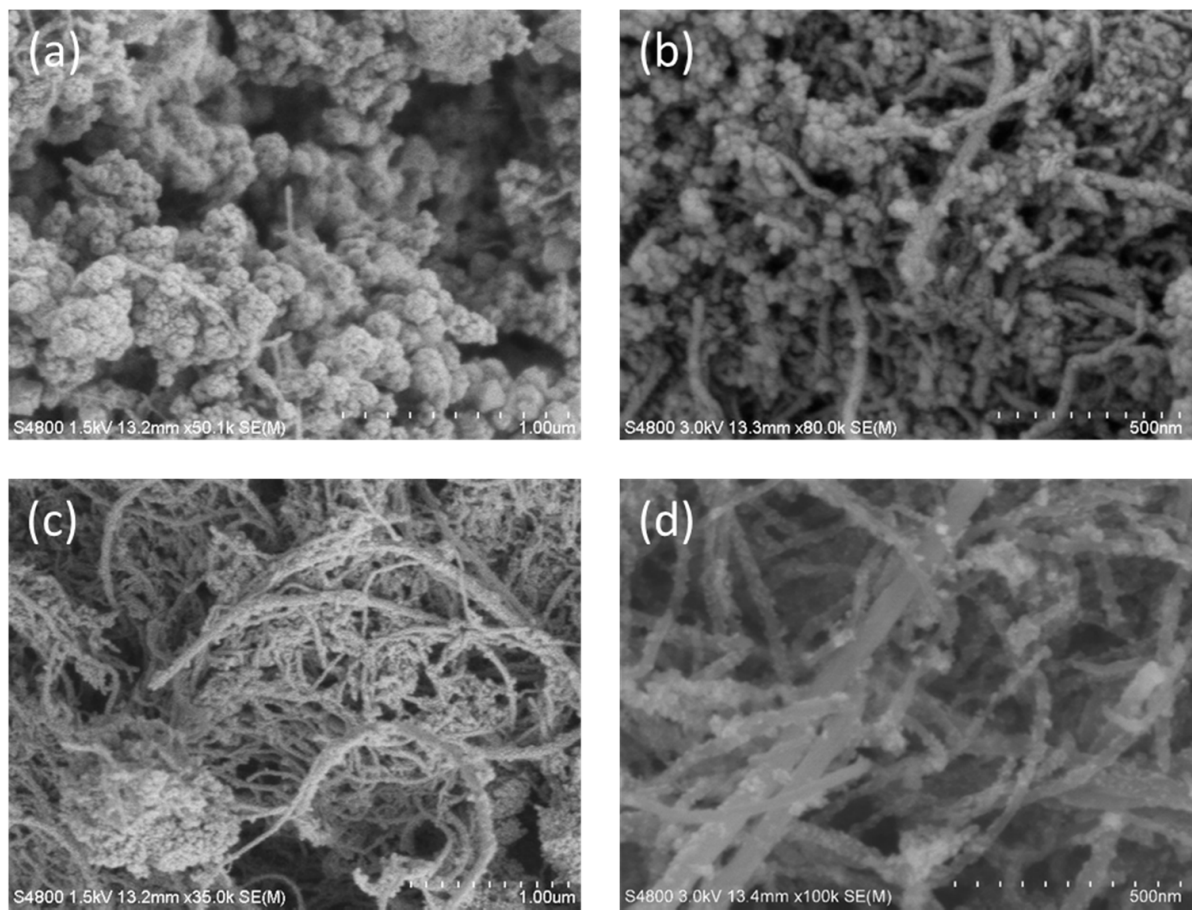

Figure 4. SEM images of the $\mathrm{NiFe}_{2} \mathrm{O}_{4} / \mathrm{MWCNTs}$ composites synthesized with different amount of carbon nanotubes (a) $0.05 \mathrm{~g}$; (b) $0.1 \mathrm{~g}$; (c) $0.15 \mathrm{~g}$ and (d) $0.2 \mathrm{~g}$.
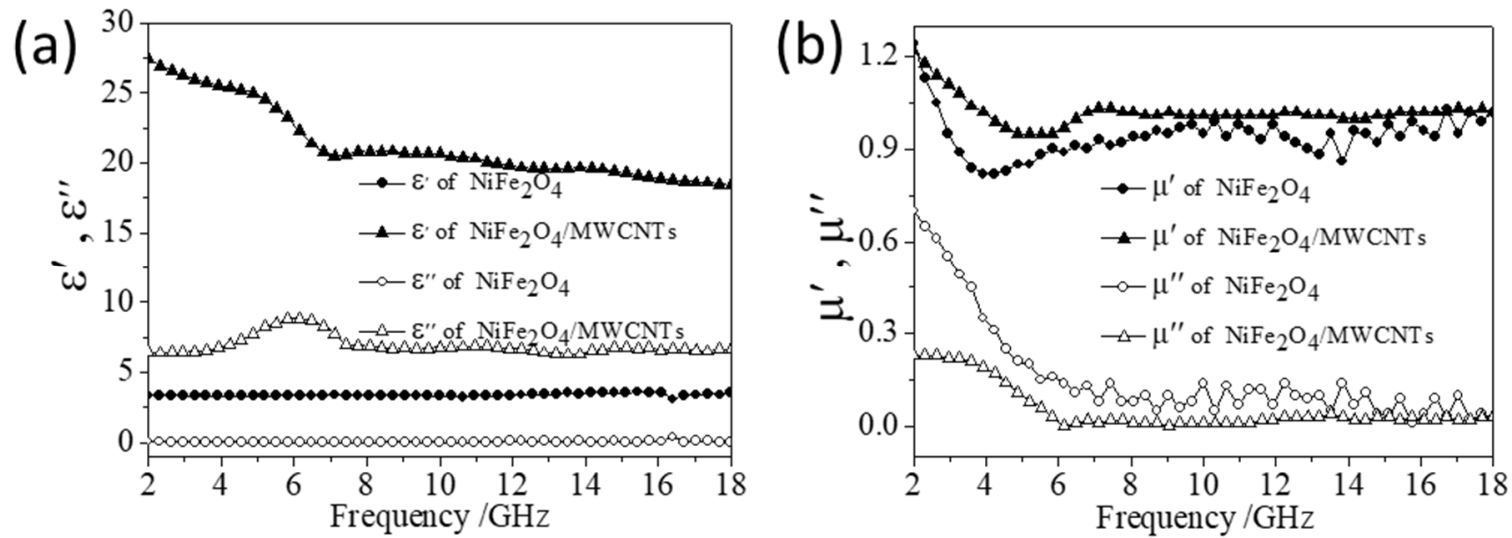

Figure 5. The electromagnetic parameters of (a) $\mathrm{NiFe}_{2} \mathrm{O}_{4}$ and (b) $\mathrm{NiFe}_{2} \mathrm{O}_{4} / \mathrm{MWCNTs}$ composites.

Figure 6 shows the color map of reflectivity values calculated from the measured electromagnetic parameters of $\mathrm{NiFe}_{2} \mathrm{O}_{4}$ sample and $\mathrm{NiFe}_{2} \mathrm{O}_{4} / \mathrm{MWCNTs}$ composite. It is obvious that the matching thickness of $\mathrm{NiFe}_{2} \mathrm{O}_{4}$ sample is $8-10 \mathrm{~mm}$, the absorption band is narrow and concentrated in the high frequency region or low frequency region. This is because that $\mathrm{NiFe}_{2} \mathrm{O}_{4}$ belongs to the magnetic absorbing materials. While the electromagnetic wave can effectively enter the material inside, because of its small relative complex permittivity, larger thickness is required for effective electromagnetic wave attenuation. Meanwhile, the matching thickness of the $\mathrm{NiFe}_{2} \mathrm{O}_{4} / \mathrm{MWCNTs}$ composite sample decreased obviously, which is $1-3 \mathrm{~mm}$, the absorption bandwidth increased relatively.

The relationship between reflectivity and frequency of the $\mathrm{NiFe}_{2} \mathrm{O}_{4} / \mathrm{MWCNTs}$ composite sample at different thickness $(0.5-3 \mathrm{~mm})$ is given in Figure 7 . As the thickness of the composite absorber increases, the reflectivity peak moves to lower frequency. In particular, the maximum reflectivity is $-19 \mathrm{~dB}$ obtained at $11.3 \mathrm{GHz}$ and bandwidth of the reflectivity below $-10 \mathrm{~dB}$ is $2.5 \mathrm{GHz}$ when sample thickness is $1.5 \mathrm{~mm}$. The thickness leads to a variation in reflectivity and the peak of reflectivity reaches a minimum value at a 
matching thickness $1.5 \mathrm{~mm}$. The microwave absorption properties of $\mathrm{NiFe}_{2} \mathrm{O}_{4} / \mathrm{MWCNTs}$ composite in this work is superior or comparable to previous results reported in the literature. For example, $\mathrm{Zhao} \mathrm{et} \mathrm{al.} \mathrm{[24]} \mathrm{successfully} \mathrm{prepared} \mathrm{NiFe}_{2} \mathrm{O}_{4}$-polystyrene composites, which shows a minimum reflection of $-13 \mathrm{~dB}$ at $11.5 \mathrm{GHz}$ with a $-10 \mathrm{~dB}$ bandwidth over the frequency range of 10.3-13 GHz for the thickness of $2 \mathrm{~mm}$. Hou et al. [18] also fabricated $\mathrm{Fe}_{3} \mathrm{O}_{4} / \mathrm{CNTs}$ hybrids by a chemical synthesis-hydrothermal treatment method and obtained a minimum reflection loss of $-18.22 \mathrm{~dB}$ at $12.05 \mathrm{GHz}$. Chakradhary et al. [25] synthesized cobalt nickel ferrite/carbon nano-fiber composite achieving minimum reflection loss of $-19.41 \mathrm{~dB}$ in X-band. In addition, Fu et al. [26] reported a novel fabrication of $\mathrm{NiFe}_{2} \mathrm{O}_{4}$ /graphene composite with a minimum reflection loss of $-29.2 \mathrm{~dB}$ at $16.1 \mathrm{GHz}$ with a thickness of $2.0 \mathrm{~mm}$. The absorbing properties is attributed to the conductive network formed by two-dimensional sheet of graphene with a large specific surface area, the outstanding magnetic properties of $\mathrm{NiFe}_{2} \mathrm{O}_{4}$ and possible interface scattering [26]. To sum up, the approach used in the present work to design $\mathrm{NiFe}_{2} \mathrm{O}_{4} /$ MWCNTs composite shall be a cost-effective way to fabricate the microwave absorber. Compared with other wave absorbers, the sound wave absorbing ability of $\mathrm{NiFe}_{2} \mathrm{O}_{4} / \mathrm{MWCNTs}$ can be due to the enhanced absorption of multiple heterogeneous interfaces between $\mathrm{NiFe}_{2} \mathrm{O}_{4}$ and MWCNTs because of the heteronanostructure, which facilitates the enhancement of conduction loss, interface polarization, dielectric relaxations polarization and multiple reflections and scattering $[27,28]$. Specifically, carbon nanotube can not only form bridges in the hybrids network and enhance the conductivity of the absorbing materials, but also create interfaces and facilitate the interfacial polarizations.
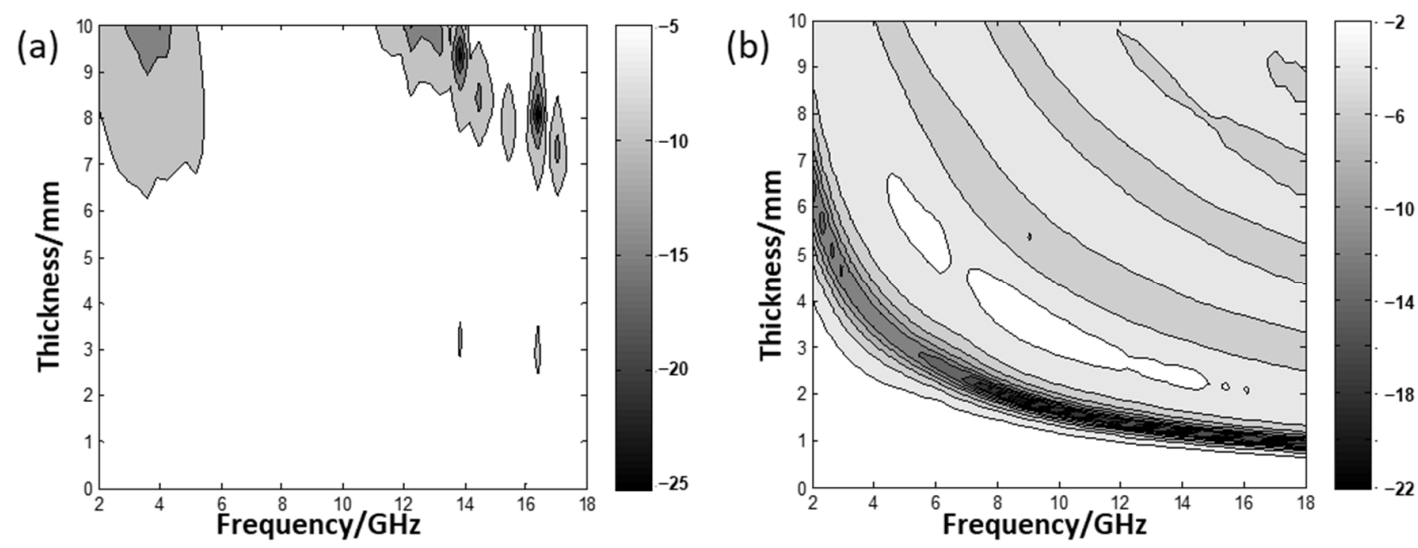

Figure 6. The color map of reflectivity values of (a) $\mathrm{NiFe}_{2} \mathrm{O}_{4}$ and (b) $\mathrm{NiFe}_{2} \mathrm{O}_{4} / \mathrm{MWCNTs}$ composite.

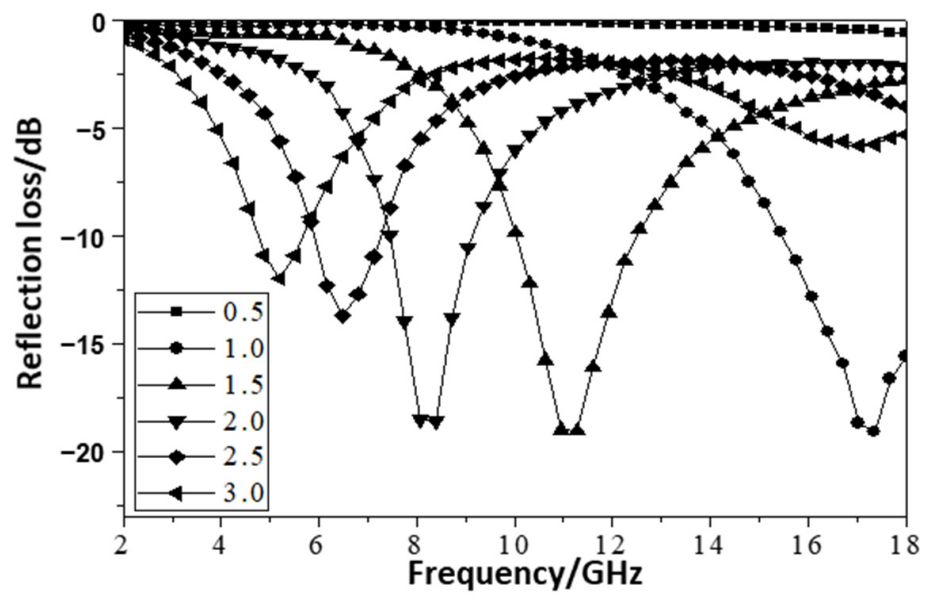

Figure 7. The relationship between reflection loss and frequency of the $\mathrm{NiFe}_{2} \mathrm{O}_{4} / \mathrm{MWCNTs}$ composite with different thicknesses. 


\section{Conclusions}

The $\mathrm{NiFe}_{2} \mathrm{O}_{4}$ and $\mathrm{NiFe}_{2} \mathrm{O}_{4} /$ MWCNTs composite absorbing materials were successfully synthesized by hydrothermal method. The sample powders were characterized with different characterization techniques. XRD analysis shows that pure $\mathrm{NiFe}_{2} \mathrm{O}_{4}$ can be synthesized with water as the reaction solvent when the reaction temperature is $200^{\circ} \mathrm{C}$ and the time is $8 \mathrm{~h}$. Scanning electron microscopy demonstrated the uniform distribution of the nickel ferrite around MWCNTs when the reaction temperature is $200^{\circ} \mathrm{C}$ and the adding quantity of multiwalled carbon nanotubes is $0.15 \mathrm{~g}$. The color map of reflectivity values demonstrates that addition of MWCNTs to the nickel ferrite could enhance the reflection loss values and reduce the matching thickness effectively. The minimum reflection loss is $-19 \mathrm{~dB}$ at $11.3 \mathrm{GHz}$ and the bandwidth of the reflectivity below $-10 \mathrm{~dB}$ is $2.5 \mathrm{GHz}$ when sample thickness is $1.5 \mathrm{~mm}$.

Author Contributions: Conceptualization, L.G.; data curation, D.C., B.D. and W.C.; formal analysis, L.G.; funding acquisition, L.G.; investigation, L.G., Y.H., D.C., B.D., W.C. and Z.D.; methodology, Y.H. and Y.L.; writing-review \& editing, Y.L. and Z.D. All authors have read and agreed to the published version of the manuscript.

Funding: This research received no external funding.

Institutional Review Board Statement: Not applicable.

Informed Consent Statement: Not applicable.

Data Availability Statement: Not applicable.

Conflicts of Interest: The authors declare no conflict of interest.

\section{References}

1. Lv, H.; Guo, Y.; Yang, Z.; Cheng, Y.; Wang, L.P.; Zhang, B.; Zhao, Y.; Xu, Z.J.; Ji, G. A Brief introduction to the fabrication and synthesis of graphene based composites for the realization of electromagnetic absorbing materials. J. Mater. Chem. C 2017, 5, 491-512. [CrossRef]

2. Zhang, K.; Gao, X.; Zhang, Q.; Li, T.; Chen, H.; Chen, X. Synthesis, characterization and electromagnetic wave absorption properties of asphalt carbon coated graphene/magnetic NiFe2O4 modified multi-wall carbon nanotube composites. J. Alloys Compd. 2017, 721, 268-275. [CrossRef]

3. Meng, F.; Wang, H.; Huang, F.; Guo, Y.; Wang, Z.; Hui, D.; Zhou, Z. Graphene-based microwave absorbing composites: A review and prospective. Compos. Part B Eng. 2018, 137, 260-277. [CrossRef]

4. Hu, J.; Zhao, T.; Peng, X.; Yang, W.; Ji, X.; Li, T. Growth of coiled amorphous carbon nanotube array forest and its electromagnetic wave absorbing properties. Compos. Part B Eng. 2018, 134, 91-97. [CrossRef]

5. Guan, B.; Liu, J.; Zhao, H.; Wu, J.; Liu, J.; Yang, F. Investigation of the microwave absorption of asphalt mixtures containing magnetite powder. Coatings 2019, 9, 813. [CrossRef]

6. $\quad$ Bhattacharyya, R.; Prakash, O.; Roy, S.; Singh, A.P.; Bhattacharya, T.K.; Maiti, P.; Bhattacharyya, S.; Das, S. Graphene oxide-ferrite hybrid framework as enhanced broadband absorption in gigahertz frequencies. Sci. Rep. 2019, 9, 12111. [CrossRef]

7. Zhang, J.; Shu, R.; Guo, C.; Sun, R.; Chen, Y.; Yuan, J. Fabrication of nickel ferrite microspheres decorated multi-walled carbon nanotubes hybrid composites with enhanced electromagnetic wave absorption properties. J. Alloys Compd. 2019, 784, 422-430. [CrossRef]

8. Lu, D.; Ramzan, M.; Ahmad, S.; Shafee, A.; Suleman, M. Impact of nonlinear thermal radiation and entropy optimization coatings with hybrid nanoliquid flow past a curved stretched surface. Coatings 2018, 8, 430. [CrossRef]

9. Zhao, T.; Jin, W.; Wang, Y.; Ji, X.; Yan, H.; Xiong, C.; Lou, X.; Dang, A.; Li, H.; Li, T. In situ synthesis and electromagnetic wave absorbing properties of sandwich microstructured graphene/la-doped barium ferrite nanocomposite. RSC Adv. 2017, 7, 37276-37285. [CrossRef]

10. Zhao, T.; Jin, W.; Ji, X.; Yan, H.; Jiang, Y.; Dong, Y.; Yang, Y.; Dang, A.; Li, H.; Li, T. Synthesis of sandwich microstructured expanded graphite/barium ferrite connected with carbon nanotube composite and its electromagnetic wave absorbing properties. J. Alloys Compd. 2017, 712, 59-68. [CrossRef]

11. Li, J.; Xie, Y.; Lu, W.; Chou, T.-W. Flexible electromagnetic wave absorbing composite based on 3D RGO-CNT-Fe3O4 ternary films. Carbon 2018, 129, 76-84. [CrossRef]

12. Hong, X.; Xie, Y.; Wang, X.; Li, M.; Le, Z.; Gao, Y.; Huang, Y.; Qin, Y.; Ling, Y. A novel ternary hybrid electromagnetic waveabsorbing composite based on BaFe11.92(LaNd)0.04 O19 -titanium dioxide/multiwalled carbon nanotubes/polythiophene. Compos. Sci. Technol. 2015, 117, 215-224. [CrossRef] 
13. Vinetsky, Y.; Jambu, J.; Mandler, D.; Magdassi, S. Cnt-based solar thermal coatings: Absorptance vs. emittance. Coatings 2020, 10, 1101. [CrossRef]

14. Rodríguez-Salinas, J.; Hernández, M.B.; Cruz, L.G.; Martínez-Romero, O.; Ulloa-Castillo, N.A.; Elías-Zúñiga, A. Enhancing electrical and thermal properties of Al6061 parts by electrophoresis deposition of multi-walled carbon nanotubes. Coatings 2020, 10, 656. [CrossRef]

15. Li, J.; Lu, W.; Suhr, J.; Chen, H.; Xiao, J.Q.; Chou, T.W. Superb electromagnetic wave-absorbing composites based on large-scale graphene and carbon nanotube films. Sci. Rep. 2017, 7, 2349. [CrossRef]

16. Zhao, T.; Ji, X.; Jin, W.; Guo, S.; Zhao, H.; Yang, W.; Wang, X.; Xiong, C.; Dang, A.; Li, H. Electromagnetic wave absorbing properties of aligned amorphous carbon nanotube/BaFe12O19 nanorod composite. J. Alloys Compd. 2017, 703, 424-430. [CrossRef]

17. Lu, S.; Xu, W.; Xuhai, X.; Ma, K.; Wang, X. Preparation, magnetism and microwave absorption performance of ultra-thin Fe3O4/carbon nanotube sandwich buckypaper. J. Alloys Compd. 2014, 606, 171-176. [CrossRef]

18. Hou, C.-l.; Li, T.-h.; Zhao, T.-k.; Liu, H.-g.; Liu, L.-h.; Zhang, W.-j. Electromagnetic wave absorbing properties of multi-wall carbon nanotube/Fe3O4 hybrid materials. New Carbon Mater. 2013, 28, 184-190. [CrossRef]

19. Li, Y.; Wu, T.; Jin, K.; Qian, Y.; Qian, N.; Jiang, K.; Wu, W.; Tong, G. Controllable synthesis and enhanced microwave absorbing properties of $\mathrm{Fe} 3 \mathrm{O} 4 / \mathrm{NiFe} 2 \mathrm{O} 4 / \mathrm{Ni}$ heterostructure porous rods. Appl. Surf. Sci. 2016, 387, 190-201. [CrossRef]

20. Fu, H.; Du, Z.-j.; Zou, W.; Li, H.-q.; Zhang, C. Simple fabrication of strongly coupled cobalt ferrite/carbon nanotube composite based on deoxygenation for improving lithium storage. Carbon 2013, 65, 112-123. [CrossRef]

21. Zhou, G.; Wang, D.-W.; Yin, L.-C.; Li, N.; Li, F.; Cheng, H.-M. Oxygen bridges between NiO nanosheets and graphene for improvement of lithium storage. ACS Nano 2012, 6, 3214-3223. [CrossRef] [PubMed]

22. Liu, W.; Shao, Q.; Ji, G.; Liang, X.; Cheng, Y.; Quan, B.; Du, Y. Metal-organic-frameworks derived porous carbon-wrapped ni composites with optimized impedance matching as excellent lightweight electromagnetic wave absorber. Chem. Eng. J. 2017, 313, 734-744. [CrossRef]

23. Feng, J.; Zong, Y.; Sun, Y.; Zhang, Y.; Yang, X.; Long, G.; Wang, Y.; Li, X.; Zheng, X. Optimization of porous FeNi3/N-GN composites with superior microwave absorption performance. Chem. Eng. J. 2018, 345, 441-451. [CrossRef]

24. Zhao, H.; Sun, X.; Mao, C.; Du, J. Preparation and microwave-absorbing properties of NiFe2O4-polystyrene composites. Phys. B Condens. Matter 2009, 404, 69-72. [CrossRef]

25. Chakradhary, V.K.; Akhtar, M.J. Absorption properties of CNF mixed cobalt nickel ferrite nanocomposite for radar and stealth applications. J. Magn. Magn. Mater. 2021, 525, 167592. [CrossRef]

26. Fu, M.; Jiao, Q.; Zhao, Y. Preparation of NiFe2O4 nanorod-graphene composites via an ionic liquid assisted one-step hydrothermal approach and their microwave absorbing properties. J. Mater. Chem. A 2013, 1, 5577-5586. [CrossRef]

27. Shu, R.; Zhang, G.; Wang, X.; Gao, X.; Wang, M.; Gan, Y.; Shi, J.; He, J. Fabrication of 3D net-like MWCNTs/ZnFe2O4 hybrid composites as high-performance electromagnetic wave absorbers. Chem. Eng. J. 2018, 337, 242-255. [CrossRef]

28. Wen, B.; Cao, M.-S.; Hou, Z.-L.; Song, W.-L.; Zhang, L.; Lu, M.-M.; Jin, H.-B.; Fang, X.-Y.; Wang, W.-Z.; Yuan, J. Temperature dependent microwave attenuation behavior for carbon-nanotube/silica composites. Carbon 2013, 65, 124-139. [CrossRef] 